\title{
Training Requirements for Control Room Operators of an Advanced Nuclear Power Plant
}

\author{
Hong Joon Park ${ }^{1}$, Geun Ok Park ${ }^{2}$, Sa Kil Kim², Seong Nam Byun ${ }^{1}$ \\ ${ }^{1}$ Department of Industrial \& Management System Engineering, KyungHee University, Yongin, 446-701 \\ ${ }^{2}$ Korea Atomic Energy Research Institute (KAERI), Daejeon, 305-353
}

\begin{abstract}
Objective: The aim of this study is to identify the training requirements of new nuclear power plant by a comprehensive literature review. Background: The design of instrumental and control systems for New NPP is applied fully digitalized systems. For example, soft-control, large display panels(LDP), and an advanced alarm system were applied to the APR-1400 or SMART. Method: The NUREG-0711 and international guideline of training program was analyzed from the following four phases of SAT(Systemic Approach to Training): Analysis, Design, Development, Implementation and Evaluation. Results: To identify the requirement of training program, 'Feedback' phase was considered and each phase of SAT was classified. Conclusion: A more systematic requirement of training program is needed which considers the computerized system was applied to the new NPP. Application: The results of the publishing can be useful for standardization of the systematic training program for the operators of NPP.
\end{abstract}

Keywords: Training program, Systemic Approach to Training(SAT), SAT requirements, Human errors

\section{Introduction}

국내 원자력법 제91조에서는 면허를 받은 자만이 운전 업 무를 수행할 수 있도록 규제하고 있으며, 일정교육을 이수 하고 면허자의 지시나 감독 하에 원자로의 운전이 부분적으 로 허용되고 있다. 그리고 발전용 원자로나 $10 \mathrm{MW}$ 열출력 이상의 연구용 원자로 면허자는 매 3 년마다 보수교육을 받 도록 되어 있다. 또한 주제어실 운전 업무를 안전하고 효율 적으로 수행하는데 필요한 지식, 기술, 그리고 실무능력을 제고하고 설비, 절차서, 그리고 규제 등의 변경사항을 습득 하도록 재교육을 실시하고 있다. 재교육은 연 3회, 회당 3 주 간(114시간) 실시되고 있으며, 강의, 토의, 실습, 그리고 기 타 교육방법으로 원자력교육원과 각 원전 본부 교육훈련 센
터에서 시뮬레이터를 활용하여 실시되고 있다.

시뮬레이터를 활용한 교육훈련은 주제어실의 상황별 대처 능력을 향상시키기 위한 목적으로 수행되고 있다. 주제어실 의 상황은 정상(Normal), 비정상(Abnormal), 그리고 비 상(Emergent) 상황으로 구분되며, 상황별 진단, 조치방법, 그리고 조치절차 등에 대한 실무교육이 주가 된다. 이러한 시뮬레이터를 활용한 교육훈련은 지식, 기술, 그리고 능력 (Knowledge, Skill, Abilities; KSAs) 위주의 교육으로 특 정 훈련상황에 대한 대처능력은 향상되나, 예상치 못한 인적 오류(Human Errors)를 예방하지 못하는 한계가 있다.

국내 원전 운영사는 미국 INPO(Institute of Nuclear Power Operations)에서 개발한 HPES (Human Performance Enhancement System)를 한국형 인적 오류 사례 분석시스템 $(\mathrm{K}-\mathrm{HPES})$ 으로 개발하였다. $\mathrm{K}-\mathrm{HPES}$ 는 사고

Corresponding Author: Seong Nam Byun. Department of Industrial \& Management System Engineering, KyungHee University, Yongin, $446-701$. Mobile: +82-10-6339-7081, E-mail: snbyun@khu.ac.kr Copyright@2013 by Ergonomics Society of Korea(pISSN:1229-1684 eISSN:2093-8462). All right reserved.

(c) This is an open-access article distributed under the terms of the Creative Commons Attribution Non-Commercial License(http://creativecommons.org/licenses/by-nc/3.0/), which permits unrestricted non-commercial use, distribution, and reproduction in any medium, provided the original work is properly cited. http://www.esk.or.kr 
개연성이 있는 사고근접 사례(Near Miss) 도 분석 대상에 포함시키고 있으며, 웹(Web) 기반 시스템의 구축을 통해 사건 제보자의 익명성을 보장하고 사건의 원인 추적성을 높 이고 있다. 또한 국내 원전 운영사는 인적 오류 예방도구(예, 인적 행위 관련 신규절차서)의 활용을 증대시키고 있으며, 인적 오류 예방교육을 정규교육 과정에 개설하여 실시하고 있다.

그러나 현재 운영사에서 실시하고 있는 운전원 교육훈련 은 각 해당 업무에 대한 체계적 절차에 의해 이행되는 것이 아니라 일방적인 주입식 교육으로 수행되고 있다(Lee, D.H., et al., 2007). 이에 따라 한국원자력안전기술원(KINS)은 SAT (Systematic Approaches to Training) 기법을 적용하 여 운전원의 직무에 따른 교육훈련의 필요성, 요구사항, 계 획, 이행, 그리고 평가 등의 일련의 과정을 체계적으로 적용 하는 교육훈련의 필요성을 제기하고 있다(KINS, 2007)

또한, 한국이 독자적으로 개발하여 UAE 원전에 수출하기 로 결정된 3세대 원전 모델인 $\mathrm{APR}-1400$ 이나 표준 설계인 가를 획득한 중소형 원자로 SMART(System-integrated Modular Advanced ReacTor)의 주제어실 (Main Control Room; MCR)은 컴퓨터를 기반으로 운전원 개인용 워크스테 이션 시스템(Workstation Display System; WDS)으로 기 존 수직 제어반에 해당하는 대형정보패널 (Large Display Panel; LDP), 터치스크린(Touch Screen)을 이용한 소프트 제어기(Soft Control), 첨단 경보시스템(Advanced Alarm System) 등 최신의 설비를 적용하여 설계된다. 이러한 첨 단의 인간-기계 인터페이스 계통(Man-Machine Interface System; MMIS)의 설계는 운전원들이 직접 제어기기로 이 동하여 확인하고 조작하였던 기존 가동 중 원전 $\mathrm{MCR}$ 구성 과는 전혀 다른 운전 환경을 갖는다. 이는 주제어실 운영을 위해 요구되는 파라미터들을 수시로 확인하는 모니터링 활동, 각 절차 단계에 대한 의사결정 활동, 그리고 연속적인 단계 들을 수행하기 위한 기억 활동 등과 같이 높은 수준의 인지 적 활동을 운전원에게 요구하고 있다(NUREG/CR 6634).

본 연구의 목적은 디지털 기반으로 설계 개념이 진화한 국 내 신규 원전 주제어실 운전원의 교육훈련을 체계적으로 정 립하기 위해 요구되는 요건을 선별하는데 있다. 도출된 교육 훈련 요건은 신규 원전을 건설한 후 운영이 가능한 교육훈련 체계를 수립할 수 있으며, 인적 오류로 인한 사건/사고를 저 감시키는 도구로 사용될 것이다. 체계적으로 개발된 교육훈 련 프로그램은 국내 신규 원전뿐만 아니라 해외 원전 수출 시 운영 단계에서부터 체계적으로 준비하고 시행할 수 있는 교육훈련 프로그램을 수립할 수 있을 것이다.

본 논문은 NUREG-0711을 기반으로 한 교육훈련 프로 그램 개발 요건에서 $\mathrm{CFR}$ 및 국제기준을 참조하여 교육훈련 개발을 위한 요소들을 비교 및 분석하여 신규 발전소 운영을
위한 운전원 교육훈련 요건을 제시한다.

\section{Training Requirements}

\subsection{CFR(Code of Federal Regulation)}

10.C.F.R. Part 50에서는 발전용 원자로 시설의 인 · 허가 를 건설허가와 운영허가로 구분하고 각각의 허가심사에 필 요한 허가 신청자료의 제출을 규정하면서 제출자료와 연관 된 기술 요건을 명시하고 있다. $\mathrm{CFR}$ 에서는 교육훈련은 직무 와 업무에 대한 체계적 분석 및 수행이 가능하며, 훈련에 따 른 직무/업무 수행도를 예측한 결과로부터 학습목표 개발할 수 있어야 한다고 제시하고 있다. 또한, 학습목표에 기반한 훈련 설계 및 시행을 통해 훈련 중 훈련생의 학습목표에 대 한 숙련도 평가가 가능해야 하며, 직무 환경에서 훈련을 받 은 직원의 수행도를 기반으로 훈련 프로그램에 대한 평가 및 개정을 할 수 있어야 한다고 명시하고 있다. 교육훈련 프 로그램을 수립하기 위해서는 다음과 같은 인간공학 분석 결 과가 학습목표에 반영되어야 한다.

- 인허가 근거

- 운전 경험 검토

- 기능 분석 및 할당

- 직무 분석

• 인적 신뢰도 분석

• MMI 설계

- 발전소 절차서

• 인간공학 확인 및 검증

\subsection{NUREG-0711}

NUREG에서는 신규 발전소 인가 신청에 대한 인간공학 규제 요건과 관련하여 훈련 프로그램 개발을 확인할 수 있는 활동들로 다음을 제시하고 있다.

• 수행되는 직무 및 작업의 체계적인 분석

- 훈련 후 수행도 분석으로부터 도출되어야 할 학습목표 개발

• 학습목표에 근거한 훈련 프로그램 설계 및 이행

- 훈련기간 중 피 훈련자의 학습목표 성취도 평가

- 현장투입 후 피 훈련자의 수행도에 근거한 훈련 평가 및 개선사항 도출

또한, 훈련 프로그램은 직무 분석 및 인간 신뢰도 분석 결 
과에 근거하여 개발하여야 하며, 훈련 범위를 결정하는데 다 음과 같은 요소를 고려하여야 한다.

- 피 훈련자 범주(예: 발전부장, 원자로 운전원 등)

- 발전소 조건(예: 정상, 비상 등)

- 종사자 업무(예: 운전, 유지 및 보수, 시험 등)

• 인간-시스템연계 설비

훈련 프로그램 개발 및 이행조직의 역할과 책임, 조직과 구성원의 자격 등은 구체적으로 정의하여야 하며, 훈련 프로 그램 이행에 활용되는 설비 또한 명확하게 정의하여야 한다.

훈련 프로그램의 학습목표는 운전원 직무 관련 지식 및 숙 련기술들을 포괄적으로 포함하여야 하며, 훈련생에게 요구되 는 다음과 같은 성취도 관련 분석에 근거하여 수립하여야 한다.

- 인허가 관련 문서 - 최종안전성분석보고서, 운전절차 서 등

- 운전 경험 검토 - 선행훈련 프로그램의 미비점 및 긍정 적 측면 등

- 기능 요건 분석 및 기능할당 - 새로운 기능 혹은 기능 변경 등

- 직무 분석 - 협업, 높은 작업부하, 특별한 숙련기술 등이 수반되는 직무

- 인간신뢰도 분석 - 원자력 발전소의 안전성에 심각한 영 향을 미칠 수 있는 인적 행위와 인적 오류 방지 및 사고 완화를 위한 운전원간 역할 조정

- 인간-시스템연계 설계 - 운전원의 선행지식 및 예상과 불일치 할 수 있는 설계 특성

- 절차서 개발 - 발전소 안전과 관련하여 대폭 개정된 절 차 단계

- 인간공학 확인 및 검증 - 확인 및 검증과정에서 규명된 인간-시스템연계 및 운전원 수행도 관련 현안

훈련 프로그램 내용에는 사실적 지식, 숙련기술, 의사결정 규칙 등이 종합적으로 포함되어야 하며, 피 훈련자가 습득한 내용을 실제 작업 환경에서 적용할 수 있도록 체계적이고 구 조화되어야 한다.

훈련 프로그램에는 피 훈련자의 성취도 평가를 위한 평가 방법 및 기준을 정의해야 하며, 훈련 프로그램 개선을 위한 절차를 수립하여야 한다. 또한 설계변경사항이 발생한 경우 에 대한 훈련은, 변경사항 관련 지식 및 숙련기술 습득의 필 요성을 분석하고, 이를 훈련 프로그램에 반영하여야 한다.

훈련 프로그램 개발과정에는 다음과 같은 사항을 포함하 여 문서화하여야 한다.
- 훈련 프로그램 요건(예: 학습목표, 규제 요건 등)

- 훈련 프로그램 내용(예: 훈련 시나리오, 훈련 일정 및 방 법 등)

- 훈련 프로그램 전반에 대한 관리 절차(예: 피 훈련자 평 가, 훈련 프로그램 개선 등)

\subsection{IEEE 845}

IEEE 845 '원자력 발전소의 인간-시스템 수행도 평가에 대한 지침'은 원자력 발전소의 시스템, 장비, 설비와 관련하 여 인간-시스템 수행도를 평가하기 위한 지침을 제공하고 있다. 자세한 평가기술을 기술하고 있으며, IEEE 1023과 같 이 원자력 발전소의 설계, 가동 및 유지에 접근한 통합시스 템에서의 적용원리를 설명하고 있으며 다음과 같은 상세기 술기준을 포함하고 있다.

- 기본 요건

- 인간-시스템 수행도 측정 요건

- 평가기술 요건

특히, 평가기술과 관련하여 체크리스트, 질문과 인터뷰, 실 측, 전문가 판단, 실험 등 수행도를 평가할 수 있는 기술들의 장단점을 나열하고 있다.

\subsection{ANSI/ANS-3.1}

원자력 ANSI/ANS 3.1 '발전소 종사자의 선발, 자격, 그 리고 훈련'은 원자력 발전소 종사자의 선발, 자격, 그리고 훈 련에 대한 기준을 제시한다. 원자력 발전소의 안전하고 효율 적인 운전에 적합한 운전 종사자원의 자격은 최소한의 교육, 경력, 그리고 훈련 요구사항으로 규정하고 이에 대해 제시하 고 있다.

이 표준의 명시된 요건들은 시험, 이동성 장치, 그리고 연 구용 원자로들에 적용하지 않고, 특별한 부서의 명칭 또는 조직적인 직무의 책임을 규정하기 위함이 아니다. 각 관리 조직은 조직 구조, 책임, 그리고 운영 기관 내 개인책임에 대 한 정의가 요구되어지며 자격 요건은 교육, 경험과 훈련을 포함하고 있으며 다음과 같은 요건에서 상세기술기준을 포 함하고 있다.

- 기능수준과 책임할당 요건

- 자격 요건

- 선발 요건

-훈련 요건 
특히, "훈련 요건"에서는 운전 조직원들의 자격은 훈련 프 로그램을 통해 발전되고 지속되어져야 한다고 언급하고 있 으며, 객관적인 훈련 프로그램들은 면허에 따른 능숙함과, 기술적 설명서들과 적용 규칙을 지키면서 안전하고 효율적 인 방법으로 능숙하게 실행하고 유지하는 적임자를 만들어야 한다고 명시하였다.

\subsection{ANSI/ANS-3.5}

ANSI/ANS 3.5 '운전원의 훈련과 시험을 위한 원자력 발 전소 시뮬레이터'는 운전원의 훈련과 시험을 위해 원자력 발 전소 제어실의 시뮬레이터를 위한 전 범위의 기능적인 요구 사항을 제시한다. 본 기준은 시뮬레이션과 수행도와 시뮬레 이션 제어실 계측기 및 제어기의 기능적인 능력의 정도를 규 정하고 있으며, 테스트, 모바일, 실험용 원자로와 미국 $\mathrm{NRC}$ 허가를 받지 않은 원자로의 시뮬레이터에 대해서는 적용되지 않는 기준이며 다음과 같은 상세기술기준을 포함하고 있다.

일반 요구사항

- 시뮬레이터 성능 요건

- 시뮬레이션 범위 요건

- 시뮬레이터 운영자 작업대 성능 요건

평가 요건

- 시뮬레이터 성능기준 요건

- 시뮬레이션 범위 요건

-시뮬레이터 운영 장소 성능 요건

-시뮬레이터 평가 요건

시뮬레이터 형상관리 요건

- 설계기준 요건

-시뮬레이터 범위 개정 요건

•시뮬레이터 변화 통합 요건

\subsection{SAT}

교육훈련을 수행함에 있어 기본적인 접근 방식은 교육훈 련을 효율적이고 효과적인 방법으로 달성해야 한다는 것이 다. '체계적인 교육훈련접근법 (Systematic Approach to Training; SAT)'은 교육훈련에 있어서 세계적으로 가장 실 용적인 방법으로 인식되고 있으며 원자력 교육훈련에서도 '원자력발전요원의 훈련과 평가에 관한 IAEA 지침서'에서 $\mathrm{SAT}$ 의 사용을 권고하고 있다.

$\mathrm{SAT}$ 는 훈련 프로그램과 훈련 활동의 지속적인 개선을 위 한 방법들을 제공하며 개개인의 강사들에게 훈련자료와 훈
련기법을 향상시키도록 도와준다. 그리고 훈련을 설계하고 개발하며 아울러 훈련생의 요구를 충족하는지를 확인하게 해준다. 또한 훈련생이 그들의 업무 수행을 위해 요구되는 능력을 배운다는 확신을 배양해준다.

$\mathrm{SAT}$ 는 가장 효과적이고 효율적인 방법으로 적용하여 훈 련과정을 분석, 설계, 개발, 수행 및 평가하기 위해 만들어져 야 하며 평가는 미래에 수행하는 훈련 활동의 강화와 개발이 연속적으로 이루어 질 수 있도록 하기 위해 실시되어야 한다.

$\mathrm{SAT}$ 를 바탕으로 하는 훈련과정은 훈련 대상자들을 성과 중심으로 평가하며 훈련 프로그램의 평가를 중요시하기 때 문에 훈련과정이 훈련목적을 충족하는지 증명하는 것이 가 능하다. SAT는 직무와 훈련 필요성 분석 (Analysis of jobs and training needs), 훈련 프로그램의 설계(Design of training programs), 훈련자료 및 교재 개발(Development of training materials), 훈련과정의 수행(Implementation of training), 훈련 효과의 평가(Evaluation of training effectiveness) 등 총 다섯 단계로 구성되며 Figure 1에 나 타내었다. 이 다섯 단계가 하나의 주기로 훈련과정의 개선 활동이 수행됨과 함께 각 단계에 피드백(Feedback) 된다. 직무와 관련된 분석 설계 개발 단계는 훈련 활동의 사전에 수행되며 수행 단계는 훈련 활동 중에 이루어지고 마지막으 로 훈련 활동 후에는 평가 단계가 실행된다.

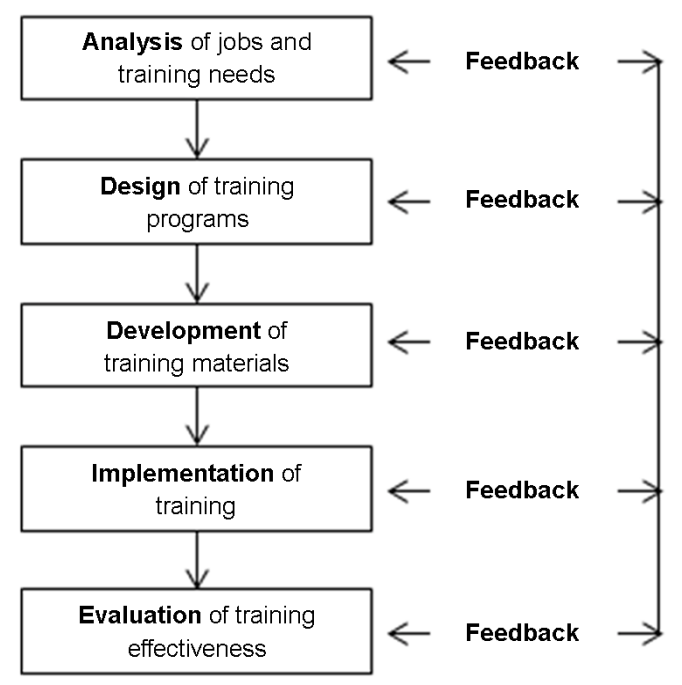

Figure 1. The process of SAT

$\mathrm{SAT}$ 의 교육훈련 과정에서 정의하고 있는 세부 요건들은 본 연구의 교육훈련 요건 개발의 구성 요소로 활용하였다. 


\section{Results}

교육훈련 요건 구성은 NUREG-0711을 기반으로 한 교 육훈련 프로그램 개발 요건에서 (1) SAT 체계에서 제시하 는 각 단계(분석, 설계, 개발, 수행, 평가)별 세부 요건으로 기본적인 틀을 구축하고, (2) 교육훈련 프로그램을 구축하 기 위해서 반드시 요구되지만, 자세한 기술적 정보가 취약한 "개정 및 보완(피드백)" 단계를 추가한 후, (3) NUREG0711의 교육훈련 요구사항에 적합한지 확인하고 (4) 도출 된 요건들의 부적합한 측면을 수정 및 보완하는 과정을 통 해 수행되었다. 또한 교육훈련체계가 국내 원전 환경에 최적

Table 1. The requirement of systemic approach training

\begin{tabular}{l}
\hline 1. Analysis phase \\
\hline 1.1 Training needs analysis \\
\hline 1.2 Job and task analysis \\
\hline 1.3 Selecting tasks for training \\
\hline 1.4 DIF analysis \\
\hline 2. Design phase \\
\hline 2.1 Selecting learning objectives \\
\hline 2.2 Identifying learning objectives \\
\hline 2.3 Establishing testing requirements \\
\hline 2.4 Job performance measures \\
\hline 2.5 Training program description \\
\hline 3. Development phase \\
\hline 3.1 Selecting training methods \\
\hline 3.2 Developing lesson plans \\
\hline 3.3 Developing training materials \\
\hline 3.4 Demonstration \\
\hline 4. Implementation phase \\
\hline 4.1 Preparation training \\
\hline 4.1 Operating training \\
\hline 4.2 On-the-job training \\
\hline 4.3 Learning effect evaluation \\
\hline 4.5 Recording performance evaluations \\
\hline 4.6 Reporting the results of evaluation \\
\hline 5. Evaluation phase \\
\hline 5.1 In-training evaluation \\
\hline 5.2 Training impact measurement \\
\hline 5.3 Training program audit \\
\hline 6. Feedback and revision \\
\hline
\end{tabular}

화될 수 있도록 국내 원전 환경 요소를 요건 구성에 반영하 였다. 도출된 교육훈련 요건은 Table 1 과 같으며, 요건 구성 을 위한 NUREG-0711의 요구사항과 SAT 체계 각 단계 별 관계도는 Figure 2 와 같다.

\subsection{Analysis phase}

$\mathrm{SAT}$ 의 첫 단계는 분석 단계로 기술담당자 과정책임자 강 사가 훈련시켜야 될 역량을 구체화하기 위하여 훈련과정개 설에 관한 일반적인 필요성을 분석한다. 기술담당자는 훈련 과정에 참여할 최소한의 훈련생 자격을 결정한다. 이들도 마 찬가지로 예상 훈련생의 대한 구체적인 훈련 필요성과 과정 에서 얻어지는 역량을 도출한다.

IAEA 훈련과정은 훈련과정으로부터 얻는 역량을 개발하 기 위해서 훈련생 중심으로 목표를 세워야 한다. 훈련주제와 친숙한 훈련생의 초기 수준을 이해하는 것이 중요하다. 훈련 재료를 개발하는 사람은 훈련생 수준을 반드시 알아야 하며 훈련생에게 필요한 교육을 제공한다는 확신을 훈련생에게도 제공해야 한다. 분석 단계에서 역량기술서와 세부과정개설 필요성이 산출된다.

첫째는 IAEA 훈련과정을 성공적으로 종료했을 때 기술기 법 자세의 관점에서 훈련생이 할 수 있게 되는 것을 역량기 술서 목록으로 명확히 작성하여야 한다. 둘째는 그러한 강의 를 위한 세부훈련 필요성의 목록을 만들어야 한다. 세부훈련 필요성은 훈련생 자격 요건과 과정 종료 후 개인이 취득하 는 역량과의 차이점이라 할 수 있다. 분석 단계에서 강사는 IAEA가 제공하는 훈련주제와 일반적인 훈련 필요성을 검토 한다. 이것은 강사들이 강의해야 하는 세부훈련 필요성의 목 록을 작성하고 도출하기 위함이다. 도출된 훈련 필요성을 만 족시키기 위해 개발되는 역량은 구체적이고 세부적이어야 한다. 이러한 역량은 명백히 정의되어야 하며 이러한 역량은 간단한 문장으로 되어야 한다. 이 역량기술서가 설계 단계의 입력이다.

\subsection{Design phase}

설계 단계의 목적은 분석 단계에서 도출된 역량을 훈련목 적으로 바꾸는 것이다. 훈련목적이 논리적인 강의순서로 훈 련계획서에 포함되어지며 훈련생에게 필요한 재료들이 개발 된다.

훈련계획서는 다음과 같이 구성된다.

- 논리적 순서를 가진 훈련목적 목록(교과 내용)

- 이러한 훈련목적을 만족시키는 훈련 방식 


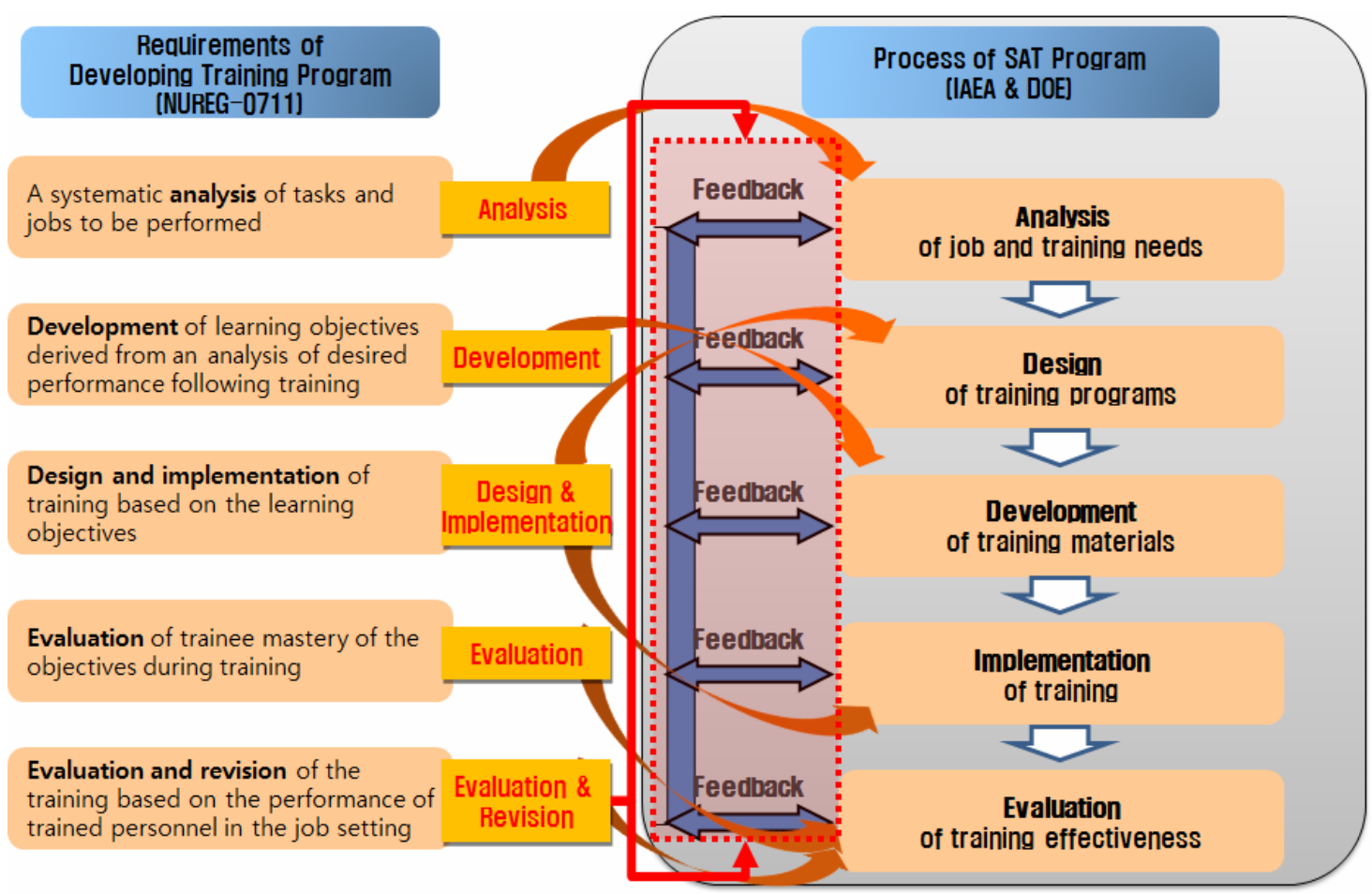

Figure 2. Mapping NUREG-0711 to SAT

- 훈련 시간 계획

- 훈련생 자격기준

- 훈련생 역량 시험 방법이나 시험 관련 서류

• 훈련재료의 승인과 검토에 대한 책임

- 훈련재료의 개발에 대한 책임

- 훈련의 개발과 수행에 소요되는 예산의 예측

첫 단계는 역량을 측정 가능한 훈련목적으로 바꾸는 작업 으로 이 단계는 훈련생 입학 요건을 만드는 작업이다. 이러 한 요건은 훈련목적을 작성하는 수준을 결정한다. 이 단계의 출력은 훈련계획서이며 훈련계획서는 훈련재료의 승인과 검 토가 포함된 프로그램 개발과 수행에 필요한 책임을 도출하 는 것이다.

사용될 교수기법은 훈련목적을 달성하기 위해 지원되는 것으로 다음과 같은 것이 있다.

- 실연 (데몬스트레이션)

- 훈련생 실습

• 케이스 스터디

- 원탁 토의

- 매개체에 의해 지원 받는 강의

- 훈련생과 강사와의 상호 행동 강의
- 역할 분담식

- 시험 개인 과제물 팀 과제물

• 문제풀이식이나 분석훈련의 복합식

훈련 보조자료는 훈련목적에 가장 적합한 것으로 선택되 며 시청각 자료, 비디오테이프나 멀티미디어, 컴퓨터 등이 사용된다.

또한, 설계 단계에서 훈련목적에 따른 훈련생 성취도를 측 정할 수 있는 시험방법이 정의된다. 훈련생 시험은 훈련생이 달성한 성취도를 훈련생에게 피드백하고 훈련과정의 효과성 을 평가하는 자료가 제공되기 때문에 중요하다. 훈련생 역량 에 대한 시험은 훈련생이 성공적으로 마쳤는지 아닌지를 결 정할 수 있다.

\subsection{Development phase}

개발 단계의 목적은 훈련과정 수행에 필요한 훈련재료를 생산하는 것이다. 개발 단계에서 강의계획서 강사준비물 훈 련생 준비물이 개발된다. 강의계획서의 목적은 강의계획안을 준비하고 강의를 하는데 도움을 주기 위해서 만들어지는 것 으로 일반적으로 다음과 같은 항목들은 강의계획서에 부분 적으로 포함된다. 
- 과정 수행을 위한 요구사항

- 훈련생 사전 시험 평가

- 강의 지침(발표자료작성 지침, 시간 계획, 요점, 질문 등)

- 강의에서 달성되는 훈련목적

- 강의자료

- 훈련생 역량 평가(시험 수행도 측정 등) 수행도 측정기 준과 시험답안이 포함되어야 함

- 기타 이동 가능한 시청각기기

- 참고자료

일반적으로 훈련생 배포자료는 각 훈련 활동을 위해 표준 화되어야 한다. 훈련생 배포자료는 유인물, 매뉴얼, 참고책자, 기초 정보자료 등 여러 가지 형태가 있을 수 있다.

훈련과정에 사용하기 위해 개발된 자료는 사용 전에 훈련 목적에 일치하고 기술적으로 정확하며 적절한가를 확인하기 위해서 반드시 검토되어야 하며 가능하다면 훈련재료는 실 제 사용에 앞서 다른 사람들에게나 작은 그룹에 검증되어야 한다. 기술담당자는 훈련에 필요한 훈련 시설과 도구의 현황 과 가용성을 검토하여야 한다. 이러한 검토의 목적은 다음과 같은 것을 확인하는 것이다.

- 훈련도구가 기술적으로 정확하고 현재 사용되는 것인가

- 훈련도구가 훈련목적에 적절한가

- 훈련도구가 훈련생이 공부하는데 도움이 되는가

- 훈련도구에 이질적인 재료가 들어 있지 않은가

위와 같은 검토는 전문가에 의해 수행되어야 한다. 기술담 당자와 과정책임자는 훈련자료의 사용의 검토와 승인에 책 임을 진다. 기술담당자나 과정책임자 둘 중 하나는 강사와 검토현황에 대해 의사소통 하여야 한다. 훈련재료의 변경은 훈련과정 시작 전에 마쳐야 한다.

\subsection{Implementation phase}

훈련과정 수행은 이전 단계에서 개발된 훈련재료와 강의 계획서를 사용하여 훈련과정을 집행하는 것으로 이 단계에 서 훈련생들은 훈련과정을 종료하며 교과목이 내포하는 역 량을 가지게 되는 것이다.

훈련을 수행하기 위한 준비에서 훈련생들이 훈련과정에 참가하도록 하는 조건을 수립하는 것이 필요하다. 훈련의 효 과성은 적절한 훈련 환경을 갖추는 것과 관련된다. 강의실이 나 실험실의 조명 냉난방 환기 조건이 충분히 갖추어 지도록 해야 한다. 훈련지역 근처에 훈련생들이 사용할 수 있는 여 가 활동 시설이 있으면 훈련과정 수행에 도움이 될 것이다. 모든 훈련생은 강사를 볼 수 있어야 하며 훈련생은 강의실에
서 적절한 공간이 주어져야 한다. 수행 단계에서 분명하게 해야 하는 일은 다음과 같다.

- 훈련과정 집행을 위해 강사의 준비사항

- 훈련과정 집행 (강의)

- 훈련생 성과 평가

교과목 모듈에 따라 강의가 수행되기 전에 강사들은 반드 시 전체 강의 내용을 검토해야 되며 특별한 주의나 설명이 필요한 부분이 있는지 확인해야 한다. 훈련재료에 어떤 변경 이 있으면 과정 시작 전에 종료해야 한다. 그리고 강사는 자 신의 조작해야 하는 훈련장비도 확인해야 한다. 강사는 필수 적으로 강의를 시작할 때 훈련목적을 언급해야 하며 강의 종 료 시 훈련목적을 다시 검토해야 한다. 좋은 교과 내용을 훈 련생에게 전달하기 위해서 강사는 그들의 강의가 전체 교과 내용에 어떻게 적합한지를 알고 있어야 하며 강의는 분명하 고 간결하게 훈련생에게 전달되어야 한다. 실제적인 예를 들 어 설명하는 것이 좋은 방법이며 특히 그 예가 강의주제나 직접 연결된 것이면 더욱 좋다. 훈련생의 관심과 주의를 강 의에 붙들어 두는 방법이 매우 중요하다. 그 방법은 아래와 같은 것이 있다.

- 토의를 활성화하여 훈련생들이 배우는 과정에 몰입한다. 강사의 질문 사례 연구의 검토 그리고 훈련생 실습과 같 은 것들이 훈련생의 토의를 촉진시키는 방법이 된다.

- 훈련생들이 역량 개발의 역할 분담이나 성과 측정에 참 여시킴으로써 배우는 과정에 몰입시킨다.

- 강의의 중요한 것이 수업 중 언제 소개되는지 훈련생에 게 질문한다.

- 실제 경험과 중요한 강의 주제를 연결시킨다.

- 천천히 그리고 분명히 말한다.

- 강의 시간은 적절하게 배분한다.

• 수업 중 외부소음이나 제거한다.

- 성취도를 인식시킨다.

- 개인간에 훈련 그룹간에 협동을 활성화시킨다.

훈련과정 진행 중이나 종료 시 훈련생 성과의 평가는 훈련 조정의 핵심 요소이다. 이러한 평가는 훈련생이 훈련목적을 달성했는지를 결정하기 위해 필요하고 그리고 훈련생이 훈 련과정에서 제공한 역량을 습득했는지를 확인하기 위해서 필요하다. 이러한 평가는 강사나 훈련과정 수행 주체에게 훈 련과정의 효과성에 대한 피드백 정보를 주는 것이다. 훈련과 정 시작 시 수행하는 훈련생 사전 평가는 훈련전의 훈련생 수준을 평가하는 것이다. 평가로부터 얻는 피드백 정보는 훈 련과정의 필요한 개선을 할 수 있게 한다. 평가의 목적은 훈 
련과정 시작 시 훈련생에게 분명하게 전달되어야 한다. 훈련 중 훈련생 성과와 진도는 자세히 관찰되고 지속적으로 관찰 되어야 한다. 진도 측정자료는 전형적인 시험 평가로도 할 수 있고 매일의 토론 강의 중 질문 실습의 성과로도 할 수 있다. 훈련생 성과 측정은 각 과목별로 규칙적으로 할 수 있 고 훈련과정 종료 시에도 할 수 있다. 평가일정은 훈련생에 게 사전에 알려주어야 한다. 모든 시험 내용은 설계 단계에 서 추출한 훈련목적으로 바탕으로 해야 한다. 시험 결과는 채점 후 가능하면 빨리 훈련생에게 제공되어야 한다. 이러한 시험 결과는 강사와 훈련생 공동으로 검토되어야 한다. 미비 점이 도출되어야 하며 훈련생들이 개선할 수 있도록 충고도 해야 한다. 훈련생이 사전에 수집된 지침에 만족시키지 못하 고 강의 중 혼란이 오는 상황에서는 미비점이 수정되기 전까 지는 다음 단계로 넘어가는데 방해가 된다. 만약 시험 성적 결과가 만족스럽지 못하다면 강사는 추가 수업과 실습을 해 야 한다. 만약 훈련생이 기간 내 평가를 통과하지 못한다면 과정책임자와 기술담당자에게 통보해야 한다.

훈련기록 문서는 훈련과정을 수행하는데 핵심적인 부분이 다. 수행된 훈련기록과 훈련생 개인성과 기록의 두 가지의 훈련기록 형태가 필요하다. 훈련기록은 자세한 강의일정과 훈련생 출석현황 사용된 훈련시설 훈련생 배포자료 강의계 획서 훈련생 시험이다.

\subsection{Evaluation phase}

평가 단계의 목적은 훈련과정의 효과성을 결정하기 위한 것이며 또한 필요한 개정이나 개선이 어디에 있는가를 도출 하기 위한 것이며 또한 또 다른 훈련과정의 개선에 적용될 수 있는 것들을 도출하기 위한 것이다. 평가과정에서 평가되 어야 하는 훈련과정의 특성은 아래와 같다.

- 훈련 필요성: 훈련과정이 수집된 필요성을 만족하는가

-사람(강사 훈련생 평가자): 성과의 질이 수립된 지침을 만족하는가

- 재료와 도구: 재료와 도구의 질이 그 목적에 적합한가

- 과정: 훈련진도와 자격진도가 의도된 대로 수행되었는가

- 목적: 목적이 분명히 가치 있게 정의되었는가

- 시설과 자원: 시설과 자원이 훈련과정 수행에 적절히 지 원되었는가

- 비용: 훈련목적 달성에 최적 비용이 사용되었는가

평가 단계에 투입되는 피드백은 다음과 같은 것으로부터 만들어진다.

•훈련생
- 강사

- 과정책임자

- 기술담당자

• 독립적인 검토와 외부 평가

\subsection{Feedback phase}

강사는 훈련과정의 단점과 개선 필요성 그리고 보강해야 할 사항을 도출하기 위해 훈련생 시험 결과를 분석한다. 피 드백은 훈련과정의 필요한 개선점에 관한 정보를 제공하는 것이다. 지속적으로 평가하는 것은 이러한 개선이 만족스럽 고 적절한 방법으로 이루어지고 있다는 것을 나타낸다. 기술 담당자는 접수된 피드백과 훈련생 시험결과 분석의 자료를 훈련 평가 보고서로 작성한다.

\section{Discussion}

본 논문에서는 문헌 연구와 요건 분석을 통해 원전의 체계 적인 교육훈련 요건을 구축하였다. 체계적인 '교육훈련접근 법(Systematic Approach to Training; SAT)'은 교육훈련 에 있어서 세계적으로 가장 실용적인 방법으로 인식되고 있 으며 원자력 교육훈련에서도 '원자력발전요원의 훈련과 평가 에 관한 IAEA 지침서'에서 SAT의 사용을 권고하고 있다.

국내 원전산업은 디지털 기반으로 설계 개념이 진화하여, 신규 원전 주제어실 운전원의 교육훈련을 체계적으로 재정 립할 필요가 있으나, 현재 운영사에서 실시하고 있는 운전원 교육훈련은 각 해당 업무에 대한 체계적 절차에 의해 이행되 고 있지 않은 실정이다. 따라서 SAT 기법을 적용하되 국내 원전산업에 적용할 수 있고 디지털 기반의 설계 개념이 적용 된 주제어실 운전원 교육훈련에 활용될 수 있는 효율적인 교 육훈련체계가 필요한 시점이며, 본 연구의 결과는 체계적 교 육훈련을 수립하기 위한 기본 요건을 제시할 수 있을 것으로 판단된다.

\section{Acknowledgements}

This work was supported by a grant from National Research Foundation of Korea(2012M2A8A4026156). 


\section{References}

Annett, J. \& Duncan, K., Task analysis and training in design, Occupational Psychology, 41, 1967.

ANSI/ANS-3.1, Selection, qualification, and training of personnel for nuclear power plants, 1993.

ANSI/ANS-3.5, Nuclear power plants simulator for use in operating training and examination, 1994.

Bailey, R.W., Human Performance Engineering: Using human factors/ ergonomics to achieve computer system usability, 2nd edition Prentice-Hall International Edition, 1989.

IAEA-TECDOC 995, Selection, specification, design and use of various nuclear, 1998.

INPO, Control Room Teamwork Development Training: Course Administration and Facilitation Guide, National Academy for Nuclear Training, Atlanta, GA, 1993.

INPO, Human Performance Tools for Workers (INPO 06-002), 2006.

Kim, S.K. et al., "Crew Resource Management Training for Improving Team Performance of Operators in Korea Advanced Nuclear Power Plant", Proceedings of 2009 IEEE International Conference on Industrial Engineering and Engineering Management (pp. 2055-2059), Hong Kong, 2009.

Kirkpatrick, D.L., Evaluation training programs: The four levels, San Francisco, CA: Berrett-Koehler, 1994.

Lee, D.H. et al., Short-Term Human Factors Engineering Measures for Minimizing Human Error in Nuclear Power Facilities, ESK Journal, 26(4), 121-125, 2007.

Roth, E. and O'Hara, J., Integrating digital and conventional HSIs: Lessons learned from a control room modernization program, BNL letter Report J6012-T3-4-5/98, Upton, NY: Brookhaven National Laboratory, 1998.

Stanton, N.A., Salmon, P.M., Walker, G.H., Baber, C. \& Jenkins, D.P., Human factors methods: a practical guide for engineering and design, Ashgate Publishing Limited, 2005.

U.S.NRC, 10CFR50, Domestic Licensing of Production and Utilization Facilities, 1998.

U.S.NRC, 10CFR52, Licensing, Certifications, and Approvals for Nuclear Power Plants, 2007.

U.S.NRC, 10CFR55, Operator's Licenses, 2007.

U.S.NRC, NUREG-0800, Standard Review Plan for the Review of Safety Analysis Reports for Nuclear Power Plants, 2007.

U.S.NRC, NUREG-0711, Human Factors Engineering Program Review Model, 2004.

Zohar, D., A, group-level model of safety climate: Testing the effect of group climate on micro accidents in manufacturing jobs, Journal of Applied Psychology, 85(4), 587-596, 2000.

\section{Author listings}

Hong Joon Park: groovyhong@khu.ac.kr

Highest degree: MS, Department of Industrial Engineering, Kyunghee University

Position title: Ph.D. candidate, Department of Industrial \& Management Engineering, Kyunghee University

Areas of interest: Human Factors in Nuclear Power Plant, Training, HCI

Geun Ok Park: gopark@kaeri.re.kr

Highest degree: $\mathrm{PhD}$, Department of Computer Engineering, Kongju National University

Position title: Project Manager, Department of Research Reactor Engineering, Korea Atomic Energy Research Institute Areas of interest: Human Factors in Nuclear Power Plant, Training System in Nuclear Industry, Simulator, HMI

Sa Kil Kim: sakilkim@kaeri.re.kr

Highest degree: $\mathrm{PhD}$, Department of Industrial Engineering, Kyunghee University

Position title: Senior Researcher, I\&C and Human Factors Research Division, Korea Atomic Energy Research Institute

Areas of interest: Human Factors in Nuclear Power Plant, Human Factors Design, Organizational Safety and Safety Culture

Seong Nam Byun: snbyun@khu.ac.kr

Highest degree: $\mathrm{PhD}$, Department of Industrial Engineering, The University of Michigan

Position title: Professor, Department of Industrial \& Management Engineering, Kyunghee University Areas of interest: Human Factors in Nuclear Power Plant, Training, HCI, HRA

Date Received : 2013-01-21

Date Revised :2012-01-21

Date Accepted : 2013-01-25 